\title{
El horizonte de crecimiento posible según los planes urbanísticos y territoriales de las islas Baleares (España) ${ }^{1}$
}

\author{
Onofre Rullan²
}

\begin{abstract}
RESUMEN
El trabajo que se presenta trata de analizar el grado de influencia que, sobre las tendencias de crecimiento residencial y turístico de fondo, hayan podido tener los planes urbanísticos y territoriales en el caso de las islas Baleares.

Para ello se analiza la llamada capacidad de carga urbanística del territorio (CCUT) de los planes urbanísticos municipales llegándose a la conclusión que los límites que estos establecen están muy por encima de la demanda efectiva de crecimiento a corto y medio plazo. En segundo lugar, se estudia si han sido los planes de ordenación del territorio los que puedan haber modulado el crecimiento a partir de las llamadas Directrices de Ordenación Territorial (DOT) de 1999 y su desarrollo mediante los Ilamados Planes Territoriales Insulares (PTI) aprobados respectivamente en 2003, 2004 y 2005. La conclusión es que tampoco estos han supuesto freno alguno al crecimiento cuantitativo de plazas residenciales y turísticas en el archipiélago y que ha sido la política económica, y no la urbanísticoterritorial, la que ha dirigido el proceso sostenido de crecimiento.
\end{abstract}

Palabras clave: Urbanismo, ordenación de territorio, crecimiento, islas Baleares.

\begin{abstract}
This study analyses the degree of influence which urban planning and land use plans have had in the Balearic Islands, against a background of a growing number of residents and tourists.

To do so, we analysed what is known as territorial urban load capacity according to the municipal urban plans. The main conclusion that is reached is that the limits established are far higher than the effective demand for growth in the short and medium terms. Secondly, we study the Land Use Directives of 1999 and their development through the Island Land Use Plans approved in 2003, 2004 and 2005, respectively, to evaluate whether land use development plans are modulating growth. We concluded that they also did not slow the quantitative growth in the number of resident and tourist beds in the archipelago. Economic policy, not land use or urban planning policies, has shaped the sustained process of growth.
\end{abstract}

Key words: Urban development, land use planning, growth, Balearic Islands.

1 Proyecto "La funcionalización turística de las Islas Baleares (1955-2000): adaptación territorial y crisis ecológica del archipiélago" (SEJ200607256/GEOG) del Ministerio de Ciencia y Tecnología de la Dirección General de Investigación del Ministerio de Educación y Ciencia. Artículo recibido el 25 de abril de 2007 y aceptado el 8 de octubre de 2007

2 Departamento de Ciencias de la Tierra de la Universitat de les Illes Balears, Grupo de investigación sobre Sostenibilidad y Territorio (GIST) (España). Email: orullan@uib.es 
Hay una pregunta que no siempre se responde a la hora de enjuiciar la responsabilidad del planeamiento urbanístico en la transformación de ciudades y regiones: ¿Cuál es el papel que juega con respeto al crecimiento cuantitativo que experimentan urbes y territorios? Hay acuerdo en admitir que el planeamiento incide en el cómo, el qué, el dónde y el cuánto se edifica, sin embargo, su grado de incidencia real está en relación directa a la limitación efectiva que establece la "letra pequeña" de los parámetros urbanísticos derivados especialmente del qué (usos) y del cuánto (intensidades). Si estos parámetros son laxos, permisivos y conceden un amplio margen de maniobra a propietarios y agentes aquella incidencia es más teórica que real.

Dicho lo anterior ipodemos pensar que la planificación tiene algún tipo de influencia sobre el comportamiento de fondo de variables como el parque inmobiliario o la extensión de la urbanización? Dependiendo del grado de limitación que los planes establezcan, tres posibles respuestas se nos presentan ante tales interrogantes:

- La planificación urbanística y territorial ha decidido, posibilitado, incentivado y dirigido el proceso de crecimiento cuantitativo de la urbanización y el parque inmobiliario.

- La planificación se ha limitado a "ordenar" un proceso de crecimiento cuya dinámica general y dimensión no se ha controlado ni cuestionado.

- La planificación no ha tenido ninguna influencia en un proceso de crecimiento que se ha desarrollado al son de la demanda.

En este trabajo pretendemos acercarnos a la posible respuesta a los interrogantes planteados a partir de lo observado en una de las regiones de España, las islas Baleares, donde el proceso de urbanización y crecimiento turístico-residencial se encuentra en un estado más avanzado ${ }^{3}$.

\footnotetext{
3 Para una síntesis actualizada de la geografía urbana de la islas Baleares puede verse (Artigues et al., 2006). Los aspectos relativos a la ordenación territorial pueden consultarse también en (Rullan, 2007).
}

El archipiélago balear se incorpora a la órbita turística europea como destino a partir de la primera apertura económica del régimen fascista del General Franco, una apertura en términos económicos -no políticosque coincide con la recuperación económica europea posterior a la $2^{\text {a }}$ Guerra Mundial. Un primer impulso de crecimiento turístico y urbanístico que se sostiene hasta la crisis de 1973 para conocer posteriormente otras puntas de crecimiento asociadas a la incorporación a la Unión Europea (1986) y a la internacionalización del la economía española (desde 1995). En esta última etapa de globalización de la economía española han jugado precisamente un papel destacado las transnacionales turísticas de origen mayoritariamente balear (Buades, 2006).

Después de esta comprimida historia territorial que se desarrolla desde medianos del siglo XX los $4.968 \mathrm{~km}^{2}$ de las cuatro islas Baleares pobladas presentan al 2005 un cuadro geoeconómico de 983.131 habitantes $\left(198 \mathrm{hab} / \mathrm{km}^{2}\right), 423.112$ plazas turísticas y un Valor Añadido Bruto que, en ese año, superó por primera vez los 20.000 millones de euros. Para alcanzar estas cifras ha sido necesario pasar de 56,55 $\mathrm{km}^{2}$ urbanizados en 1956 a 248,09 en 2000 (Pons, 2003), consumiendo, en la actualidad, 2,7 millones de TEP en combustibles fósiles al año y generando 655 mil toneladas de residuos sólidos urbanos anuales.

\section{¿Han influido las disposiciones administrativas en la evolución territorial de las islas Baleares?}

Para responder a la cuestión planteada puede ser útil, en primer lugar, observar la cronología de la aparición de las disposiciones más importantes que la administración ha ido promulgando, en paralelo a la evolución de las variables más indicativas del proceso urbanístico y turístico seguido. Se trata de indagar en la posible influencia de tales disposiciones sobre los impulsos de crecimiento observados en las islas Baleares. La Figura № 1 sitúa las disposiciones turísticas y urbanísticas más importantes sobre la línea del movimiento aeroportuario balear, la variable sin duda más indicativa de la evolución económica de un archipiélago turístico como el estudiado. 


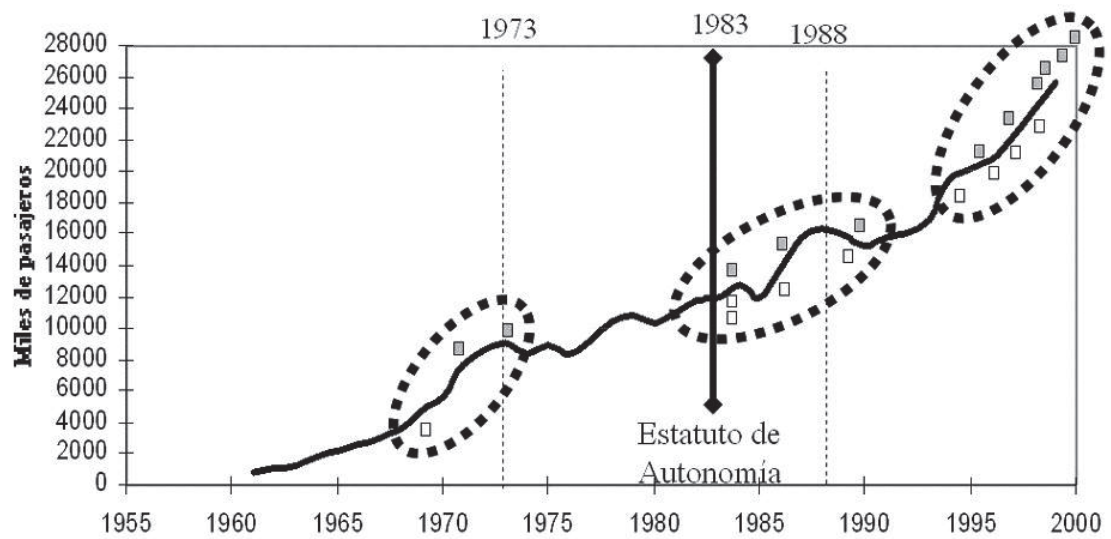

Fuente: Elaboración propia en base a http:www.aena.es (2007).

En la gráfica se representan únicamente las disposiciones que hemos considerado más relevantes ${ }^{4}$ que se han aprobado en las islas Baleares en materia turística (cuadrados grises) y urbanístico-territorial (cuadrados blancos). La gráfica abarca tanto la etapa en que las únicas administraciones actuantes eran la estatal y la municipal -hasta 1983-, como la siguiente en la que la administración autonómica -nacida a raíz del desarrollo de la Constitución de 1978- desplazó en gran medida a la central; un desplazamiento fruto de la asunción de competencias en dichas materias por parte de la recién creada comunidad autónoma.

De la observación de la gráfica se deducen fundamentalmente tres conclusiones:

- Las disposiciones legales de todo tipo se incrementan notablemente conforme el proceso se hace más maduro. Ello coincide, en el tiempo, con la asunción de competencias por parte de la Comunidad Autónoma. La fase autonómica es más

4 Para una visión completa de todas las disposiciones que han afectado a las islas Baleares puede verse (Rullan, 1999). Para una visión de conjunto de las políticas y planes de ordenación del territorio aplicados en España puede consultarse (Benavent, 2006) prolífica que la anterior a la hora de generar todo tipo de disposiciones.

- La intensificación de disposiciones de la administración guarda una relación directa con las fases alcistas del proceso de turistización del territorio balear. La primera hasta la crisis del petróleo de 1973, la segunda coincidente con la integración de España en las estructuras económicas europeas y la tercera paralela al crecimiento de la economía española asociado a su expansión internacional, en especial sobre los mercados sudamericanos.

- El proceso no parece verse alterado, en su evolución general, por las disposiciones que la administración va dictando. Ello se deduce al coincidir la tendencia general observada a escala española y europea con la tendencia particular del archipiélago balear.

Por lo tanto, estaríamos ante la tercera o, en todo caso, la segunda de las posibilidades que planteábamos más arriba: no influencia de la planificación sobre el crecimiento o, en todo caso, ordenación de un crecimiento no cuestionado. Dos opciones no excluyentes ya que pueden coexistir en diferentes municipios o islas e, incluso en un mismo espacio, pueden sucederse en el 
tiempo. Unos espacios han observado políticas que han "ordenado el crecimiento" mientras que otros simplemente lo han encajado pero ninguno lo ha controlado ni contenido. Si analizamos la línea general de crecimiento desde la generalidad de la escala archipiélago o, como máximo, insular, se observa cómo el proceso cuantitativo general se ha mostrado insensible a las políticas de las distintas administraciones.

Tal fracaso (o éxito) administrativo se debe, por una parte, al papel jugado por unas políticas económicas que han favorecido la inversión inmobiliaria frente a otros sectores productivos $y$, por otra, al rol desempeñado por el tercer nivel administrativo, el municipal, que es el que regenta precisamente la gestión urbanística del territorio. Las corporaciones locales solo en contadas ocasiones se han planteado políticas distintas a las orientadas a servir la demanda. Una regencia que, como se verá, tan solo en los últimos años ha empezado a ser matizada. En efecto, la irrupción de políticas territoriales, de escala insular o interinsular, de efectos directos sobre el crecimiento urbanístico, lleva más de 40 años de retraso frente a unas políticas municipales que, salvo contadas y recientes excepciones, se ha limitado a servir la pujante y creciente demanda.

\section{¿Influye el planeamiento urbanístico municipal?}

Dos variables parece que deberían controlar la evolución general del proceso de crecimiento urbanístico. Por una parte, lo que Ilamamos la capacidad de carga urbanís- tica del territorio (CCUT), establecida por los diferentes planes urbanísticos municipales a partir de los establecidos por los parámetros urbanísticos al uso: intensidad, usos, retranqueos, alturas, etc. Una CCUT que se va convirtiendo en oferta únicamente en la medida que el territorio se va urbanizando y los solares edificando. Por otra, la demanda que funciona con independencia de la política general turística, urbanística y territorial de la comunidad pues responde a los impulsos de crecimiento que se dan a escala suprarregional, especialmente española y europea.

Desde principios de la década de 1980 se han llevado a cabo diferentes recuentos de la CCUT de las islas Baleares. Aunque calculado con diferentes metodologías, las cifras siempre han revelado que la CCUT está muy por encima de la demanda que finalmente se ha materializado. Dicho en otras palabras, el planeamiento municipal no ha querido o no ha podido influir en el crecimiento general del proceso. El Cuadro № 1 aporta las cifras.

Como puede observarse la CCUT ha experimentado un ligerísimo descenso, menos de 200.000 plazas (que posiblemente responda a los diferentes criterios metodológicos utilizados), mientras que el parque construido se ha incrementado en más de 600.000 unidades. Un incremento que, como puede deducirse fácilmente, está provocado por la ascendente presión de la población de hecho sobre el parque residencial construido.

Los listones de crecimiento máximo posible se sitúan tan lejos de la demanda efec-

Cuadro № 1

LA CAPACIDAD DE CARGA URBANÍSTICA DEL TERRITORIO EN LAS ISLAS BALEARES DESDE 1982

\begin{tabular}{|c|c|c|c|c|}
\hline Año & $\begin{array}{c}\text { CCUT } \\
\text { (habitantes) }\end{array}$ & $\begin{array}{c}\text { Parque construido } \\
\text { residencial y turístico }\end{array}$ & $\begin{array}{c}\text { Población de } \\
\text { derecho residentes } \\
\text { más población flotante }\end{array}$ & $\begin{array}{c}\text { Población de } \\
\text { hecho en } \\
\text { temporada alta }\end{array}$ \\
\hline 1982 & 4.096 .113 & 1.150 .365 & 669.936 & 936.357 \\
1992 & 3.874 .329 & 1.652 .223 & 728.609 & 950.449 \\
1999 & 3.809 .276 & 1.789 .644 & 811.709 & 1.465 .789 \\
\hline
\end{tabular}

Fuente: Elaboración propia a partir de la serie Evolución Económica (Caixa de les Balears), datos oficiales del Govern de les Illes Balears y (Aguiló y Verger, 1982; Rullan, 1995; Blàzquez et al., 2002). 
tiva que consiguen eludir cualquier intento de control y/o contención del crecimiento general que desde el urbanismo se pudiera eventualmente plantear. Como ya apuntamos a finales de los 80 "...el planeamiento va a remolque de la estructura territorial existente. El planeamiento no tiene esquema propio, no cuenta con la fuerza necesaria como para dibujar una nueva estructura. Se ultradimensiona todo pero con los mismos patrones locacionales. No hay Ordenación del Territorio" (Rullan, 1989: 630).

Ante este cuadro de dimensiones urbanísticas, no es de extrañar que el crecimiento general de la planta residencial, contrariamente a lo que defienden determinados sectores empresariales, no haya tropezado con ninguna restricción efectiva. El parque residencial balear ha tenido un ritmo de "crecimiento anual sostenido" que ha oscilado entre el 4,1\% de Menorca, al 2,7\% de lbiza, pasando por el 3\% de Mallorca. Basta comparar las 2.019.632 plazas que separaban, en 1999, las 3.809.276 de la CCUT con la cifra de 1.789.644 del parque residencial construido. Un parque que, con estas cifras, podría multiplicarse por 2,1.

Los últimos cálculos oficiales (SITIBSA, 2002) han afinado bastante en el cómputo de la edificabilidad que los diferentes planes urbanísticos contemplan. Dicho estudio, además de evaluar la capacidad residencial del parque construido, contabiliza, a 31 de diciembre de 2001, el Ilamado suelo vacante. Un concepto este que es preciso aclarar.

El urbanismo contemporáneo se ha enfrentado especialmente a la necesidad de "construir ciudad" y, consecuentemente, en cierta medida se ha olvidado de la ciudad que "va construyéndose por su cuenta". Y no nos referimos a los procesos urbanizadores y/o edificatorios ilegales, sino a aquellos que, en nomenclatura urbanística española suelen llamarse actuaciones asistemáticas, aquellas que no requieren de la previa gestión del suelo ya que la potestad de edificar está exclusivamente en manos de sus propietarios de modo individualizado. En esta situación se encuentra la inmensa mayoría del Ilamado "suelo urbano".

En efecto, la legislación urbanística española establece una secuencia, un proceso de construcción de la ciudad que, una vez conocida la ordenación establecida por el plan, se ejecuta mediante la gestión del suelo, la urbanización y la edificación.

Sin embargo, habitualmente se admite que "dado que normalmente la edificación se puede desarrollar de manera independiente y fraccionada solar a solar, se considera que, estrictamente, la ejecución del plan comprende las dos primeras fases" (Esteban, 2003: 233). Consecuentemente, no es habitual contabilizar como ejecución de las previsiones del plan aquella edificación que no requiera de la previa gestión del suelo y urbanización. Se sigue pensando en el crecimiento de la ciudad, en términos estrictamente superficiales y sin atender ni contabilizar, cuando no escondiendo, el dimensionado de la edificación potencial en suelo ya reparcelado y transformado, es decir la mayor parte del suelo urbano.

El estudio oficial del Govern de les Illes Balears (SITIBSA, 2002) "descubre" parte de esta contabilidad oculta al cuantificar la edificabilidad $-y$ consecuentemente el potencial inmobiliario- del Ilamado "suelo vacante", aquel que aún no está ocupado por ningún tipo de edificación y que podemos encontrar en todas las clases de suelo y situaciones urbanísticas.

La metodología del estudio, al analizar el territorio a partir de fotografía aérea, no detecta aquellos edificios susceptibles de reconversión residencial ni aquellos que todavía no han agotado su edificabilidad residencial. Por esta razón, el estudio de SITIBSA solo descubre "parte" de la edificabilidad y aprovechamiento residencial y turístico vacante.

No obstante, a partir de los datos oficiales de la administración autonómica y del estudio, también oficial, de SITIBSA, pueden definirse, y en último caso deducir indirectamente, los tres estratos básicos del potencial inmobiliario de un territorio, su capacidad de carga urbanística (CCUT), a saber:

1. El parque residencial y turístico construido. Evaluado a partir de las plazas turísticas autorizadas más el número de viviendas multiplicadas por su correspon- 
diente coeficiente de hacinamiento (habitantes por vivienda). Para la fecha señalada el techo residencial y turístico construido ascendía, según los datos oficiales, a 1.872 .988 plazas.

2. El parque residencial y turístico potencial en suelo vacante. Se trata de la edificabilidad potencial que ofrecen las parcelas y solares vacíos de las islas Baleares. Tales entidades se identificaron a partir de fotografía aérea y se calculó su edificabilidad aplicándoles la normativa urbanística vigente en el municipio correspondiente. A 31 de diciembre de 2001 oficialmente ascendería a 780.117 plazas.

3. El parque residencial y turístico potencial en suelo que ha agotado total o parcialmente su edificabilidad. En el primer caso -suelo totalmente edificado- se trataría de edificios que podrían acoger nuevas plazas residenciales como consecuencia de cambios de usos o como efecto de la subdivisión de unidades residenciales existentes, se trata de un suelo que ha agotado su edificabilidad pero no todavía su aprovechamiento residencial y/o turístico; en el segundo -suelo parcialmente edificado- se trata de solares que si bien ya cuentan con algún tipo de construcción, no han agotado todo su potencial edificatorio. Este cómputo no lo aporta el estudio oficial; sin embargo, puede obtenerse restando de la CCUT (3.809.276 plazas), que anteriormente habían aportado otros estudios oficiales ${ }^{5}$, el parque construido y la capacidad en suelo vacante que sí aporta el estudio de 2002. Ello nos arroja la cifra de 1.156 .371 plazas.

El Cuadro № 2 muestra la distribución, por islas, de la CCUT descompuesta según hemos indicado en las consideraciones anteriores.

A la luz de los datos analizados, resulta evidente que el papel jugado por la administración urbanística municipal ha sido prácticamente nulo en relación a su posible incidencia en la evolución general del proceso descrito de crecimiento cuantitativo de la oferta residencial y turística. Únicamente se han dado casos concretos y muy puntuales de intervención municipal decidida con vistas a conseguir una correcta ordenación del crecimiento que, como tendremos ocasión de insistir, en muy pocos casos se plantea cuestionar.

Para completar el análisis es necesario conocer si ha habido intervención pública desde las políticas puestas en marcha desde la competencia autonómica en ordenación de territorio. A ello dedicamos el próximo apartado.

Cuadro № 2

PLAZAS EN EL PARQUE RESIDENCIAL Y TURÍSTICO CONSTRUIDO Y POTENCIAL SEGÚN ISLAS (31-12-01)

\begin{tabular}{|l|c|c|c|c|}
\hline \multicolumn{1}{|c|}{ Islas } & $\begin{array}{c}\text { Parque } \\
\text { construido } \\
\text { (Plazas) }\end{array}$ & $\begin{array}{c}\text { Suelo } \\
\text { vacante } \\
\text { (Plazas) }\end{array}$ & $\begin{array}{c}\text { Vacante en suelo } \\
\text { total o parcialmente } \\
\text { ocupado (Plazas) }\end{array}$ & $\begin{array}{c}\text { Capacidad } \\
\text { total } \\
\text { (Plazas) }\end{array}$ \\
\hline Mallorca & 1.411 .573 & 552.893 & 996.922 & 2.961 .388 \\
Menoría & 193.939 & 104.042 & 54.618 & 352.599 \\
Ibiza y Formentera & 267.276 & 123.182 & 104.831 & 495.289 \\
Islas Baleares & 1.872 .988 & 780.117 & 1.156 .371 & 3.809 .276 \\
\hline
\end{tabular}

Fuente: Elaboración propia a partir de los datos oficiales del Govern de les Illes Balears y SITIBSA (2002).

5 Entre otros, los que acompañaban la elaboración
de las Directrices de Ordenación Territorial y que
fueron facilitados por el Govern en sede parla- mentaria ante diferentes preguntas escritas plan teadas por la oposición. 


\section{¿Influyen los planes de ordenación territorial?}

No es este el momento de analizar el variado elenco de disposiciones que se han sucedido, superpuesto y reemplazado desde la escala insular e interinsular, con la teórica intención de intervenir en este galopante proceso de crecimiento, dicho análisis ya lo hemos llevado a cabo en otras ocasiones (Rullan, 1999 y 2002)

No obstante, vale la pena insistir en el análisis de las Directrices de Ordenación Territorial de 1999. Se trata, sin duda, del documento de ordenación territorial más importante de todos cuantos han sido aprobados en la materia desde la asunción de dichas competencias en 1983. Un documento que reemplaza el antiguo Plan Provincial de Ordenación de Baleares (PPOB), el plan que, desarrollando la primera ley del suelo española (1956), en su momento dio cobertura al crecimiento urbanístico de la época desarrollista.

Después de la también importante aprobación de la Ley General Turística ${ }^{7}$, el Parlamento de las islas Baleares sanciona la ley de aprobación de las Directrices de Ordenación Territorial $(\mathrm{DOT})^{8}$, la pieza angular del modelo de figuras de planificación territorial que había diseñado la Ley de Ordenación Territorial de $1987^{9}$.

Las DOT, como veremos, al tiempo que implantan algunas medidas innovadoras, consolidan el modelo territorial vigente y dan carta legal a un esquema que, si bien

6 Los análisis jurídicos de tal evolución pueden verse en (Blasco, 2002), ceñidos a la evolución de las disposiciones turísticas puede consultarse (Socías, 1998 y 2001).

7 Ley, 2/1999, de 24 de marzo, General Turística de las Islas Baleares (BOCAIB de 1 de abril de 1999).

8 Ley, 6/1999, de las Directrices de Ordenación Territorial de las Islas Baleares y de medidas tributarias (BOCAIB de 17 de abril de 1999).

9 Ley 8/1987, de 1 de abril, de Ordenación Territorial de las Islas Baleares (BOCAIB de 23 de abril de 1987). Una ley que sería reformada en 2000 pero sin afectar a la figura de las Directrices de Ordenación Territorial (BOIB de 27 de diciembre de 2000). hasta ahora no era explícito, se hallaba implícito en la aplicación combinada de los instrumentos municipales de ordenación urbanística.

Las principales medidas adoptadas por las Directrices de Ordenación Territorial (1999)

Puestos a generalizar podríamos convenir que son cinco son las medidas más emblemáticas e importantes de las DOT:

1. Se prohíbe genéricamente la nueva urbanización en núcleos de nueva planta aislados del suelo urbano y urbanizable ya existentes en el momento de aprobación de la DOT, ello con independencia que afecten o no a espacios naturales protegidos o de valor paisajístico reconocido.

2. Se prohíbe genéricamente la nueva urbanización en los primeros 500 metros desde la ribera de mar. Al respeto se crea una franja de protección, coincidente con la llamada zona de influencia de la ley de costas, las Ilamadas Áreas de Protección Territorial (APT). En el interior de la misma no puede clasificarse nuevo suelo para usos residenciales y/o turísticos, con independencia de la presencia de valores naturales y paisajísticos y de su contacto o no con núcleos preexistentes.

3. Se limita a los planeamientos urbanísticos municipales la posibilidad de clasificación de nuevo suelo para uso residencial y/o turístico. Dicha limitación se establece en el $10 \%$ del suelo urbano y urbanizable con plan parcial aprobado en 1999 para las islas de Mallorca, Ibiza y Formentera, un porcentaje que para el caso de Menorca se eleva al $12 \%$. Las hectáreas resultantes de aplicar el 10 o $12 \%$, según los casos, podrán ser repartidas entre los municipios de cada isla por parte de los Ilamados Planes Territoriales Insulares (PTI) que desarrollan las DOT y a los que se reconoce libertad de criterio a la hora de repartir en función del modelo territorial que se adopte para cada isla. Mientras los Consejos Insulares -los organismos autonómicos encargados de su redacción- no aprobaran los respecti- 
vos PTIs, los planes municipales que se iban revisando podían clasificar "a cuenta" una cantidad de hectáreas no superior al menor de los dos siguientes cómputos: $2 \%$ del suelo urbano y urbanizable con plan parcial aprobado o $3 \%$ del suelo urbano.

4. Se circunscribe del crecimiento superficial futuro al interior de una orla periurbana de $500 \mathrm{~m}$ a partir de los núcleos urbanos preexistentes en 1999. Son las Ilamadas Áreas de Transición (AT), unos "buffers" de naturaleza rústica en el interior de los cuales los planes municipales podrán elegir la ubicación de las hectáreas de nuevo crecimiento que les corresponde en función del reparto que pueda hacer el PTI de su isla o, anticipadamente, el 2 o $3 \%$ antes mencionado. Las ATs no suponen ninguna clase nueva de suelo, son de naturaleza rústica, pero resulta ser el único suelo rústico que el planeamiento municipal puede proponer su reclasificación. Se trata, de hecho, del único suelo "clasificable" para el crecimiento residencial y turístico (Figura № 2).
5. Se reclasifican automáticamente (Disposición Adicional 12a ) como suelo rústico los sectores urbanizables de uso residencial, turístico o mixto que se encuentren en alguna de las siguientes situaciones:

a) Terrenos en Suelo Urbanizable No Programado en Planes Municipales con más de 12 años de vigencia.

b) Sectores con Plan Parcial aprobado definitivamente pero sin Proyecto de Urbanización que formen un núcleo aislado o que se ubiquen en el interior de las áreas de protección territorial (APT).

c) Sectores en Suelo Urbanizable Programado fuera de plazos.

d) Terrenos en Suelo Apto para Urbanizar, con vigencia igual o superior a cuatro años, que no han iniciado la tramitación del correspondiente Plan Parcial.

Tales reclasificaciones tenían carácter definitivo en caso de tratarse de sectores aislados o incluidos en APT, los demás, los in-

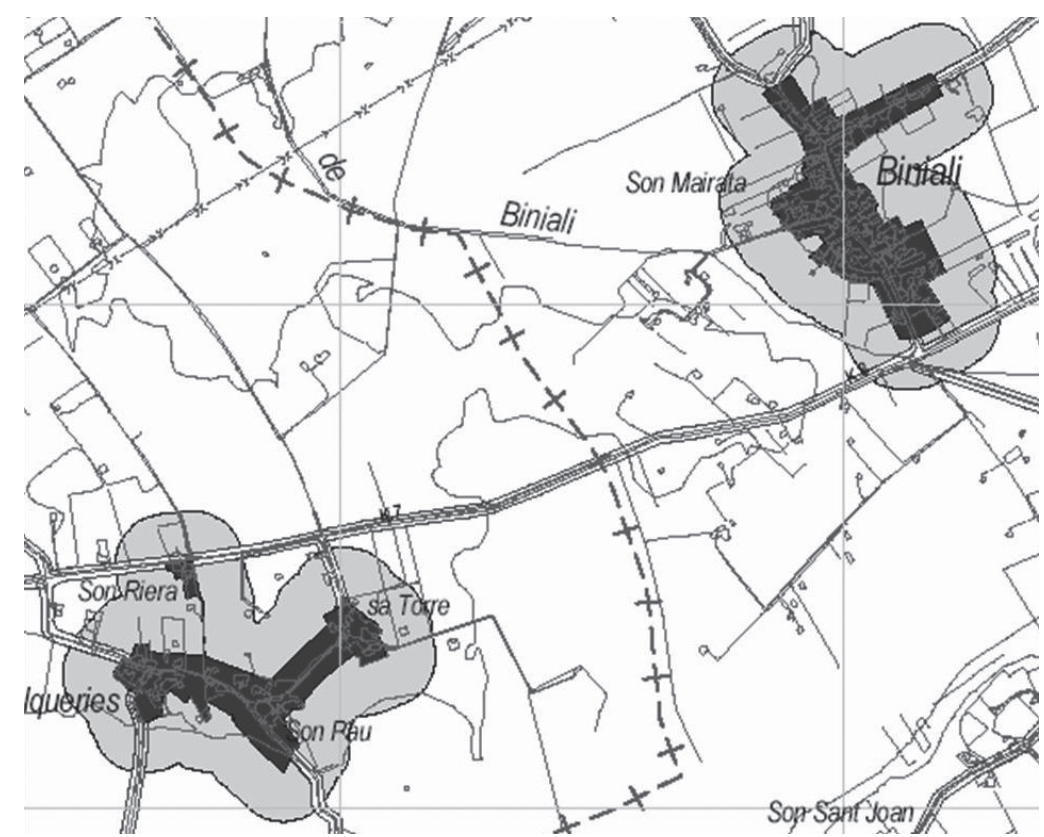

Fuente: Elaboración propia. 
cluidos en AT, podrían ser recuperados posteriormente si no superaban las superficies asignadas a los diferentes municipios al redistribuir -los PTIs- el crecimiento futuro.

\section{La redistribución del crecimiento}

Siempre en el interior de las Áreas de Transición de 500 m, las DOT prevén el crecimiento de la nueva urbanización turística y residencial que se cuantifica, como dijimos, en un $10 \%$ (12\% en Menorca) del suelo urbano y urbanizable con plan parcial aprobado para un horizonte temporal de 10 años (1999-2009). Este porcentaje se calcula sobre la superficie del suelo urbano y urbanizable con aprobación definitiva en el momento de la entrada en vigor de las DOT (18-4-99). La aplicación de tales porcentajes (10 o $12 \%$ ) sobre el suelo urbano $(20.855,48$ ha) y urbanizable con plan parcial aprobado $(6.168,72$ ha) arrojó la cifra de 2.775,62 ha (Ferrer, 2001: tabla 7). A las hectáreas resultantes para cada isla las DOT permiten asignarles un aprovechamiento equivalente de 100 plazas/ha lo que da un techo potencial a repartir de 277.562 plazas.

De esta manera se generan tres bolsas insulares de crecimiento potencial que deberán ser repartidas intermunicipalmente por los futuros Planes Territoriales Insulares. Dicho reparto debe de llevarse a cabo a partir de criterios que primen los términos municipales menos desarrollados urbanísticamente frente a los más desarrollados (Figura № 3). Tal reparto intermunicipal del nuevo crecimiento solo podrá ubicarse, como dijimos, en el interior de las orlas periurbanas antes citadas, las ATs.

En cualquier caso, resulta importante insistir en que ni las DOT, ni los PTI que las desarrollan clasifican suelo. Simplemente abren la puerta a la clasificación por parte de ayuntamientos ${ }^{10}$.

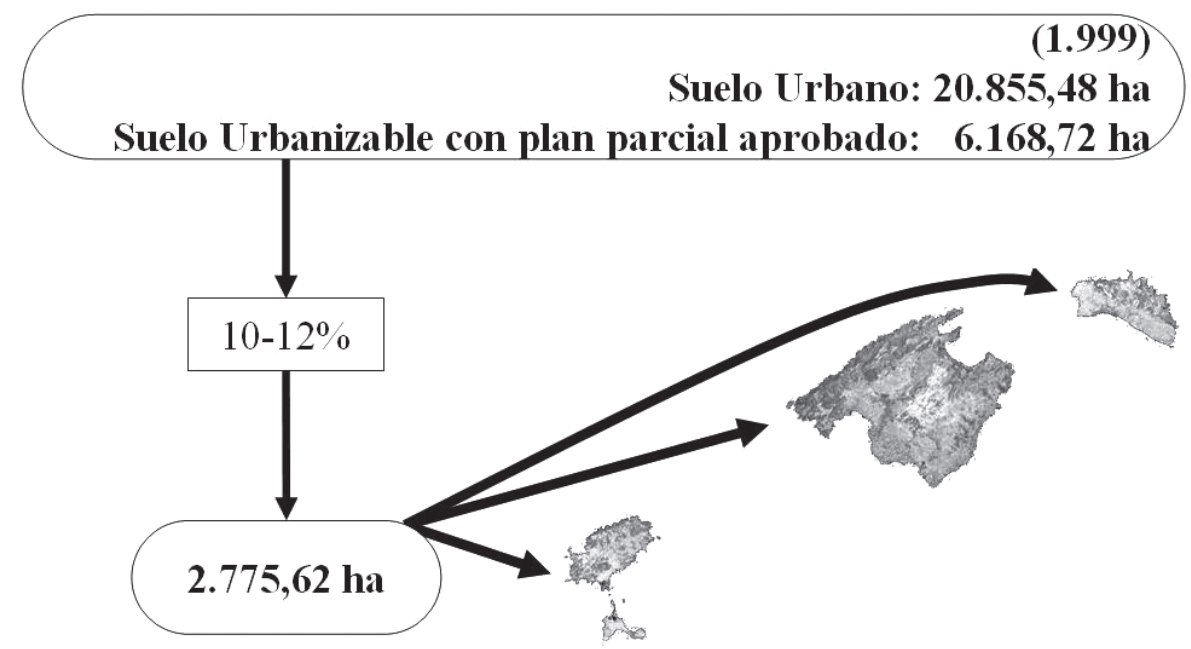

Fuente: Elaboración propia a partir de Ferrer (2001: tabla 7).

10 Recordemos aquí que la vigente Ley 6/1998, de 13 de abril, sobre régimen del suelo y valoraciones establece, con carácter general para toda España, la llamada clasificación residual del suelo urbanizable, esto es, que una vez clasificado objetivamente el urbano y el no urbanizable o rústico de valor natural o patrimonial, el resto tiene la consideración se suelo urbanizable. Sin embargo, la Disposición Adicional 4" atendiendo a la "peculiaridad del hecho insular" y su "capacidad limitada de desarrollo territorial", excepciona los territorios insulares de la aplicación del concepto de suelo urbanizable como residual después de haber clasificado el urbano y el urbanizable de especial protección. 
La publicidad que, en 1999, acompañó la aprobación definitiva de las DOT aportaba el dato, ya conocido, de una capacidad residencial y turística potencial establecida por los planes municipales de 4 o 4,3 millones de plazas (la información fue algo vacilante). Según la misma documentación, con la entrada en vigor de las DOT se rebajaría la CCUT del archipiélago en 2,3 de los 4 millones de plazas potenciales. Para reducir tales expectativas, se quiso dar a entender que la fórmula consistía en suspender o reclasificar a rústico 4.500 hectáreas de suelo urbanizable sin plan parcial aprobado (como consecuencia de lo expuesto en el punto 5 del subapartado "Las principales medidas...").

Tal propósito era y es completamente engañoso, pues para descargar 2,3 millones de plazas de la CCUT eliminando 4.500 hectáreas de suelo urbanizable, debería de tratarse de hectáreas que contasen con unas edificabilidades equivalentes a $519 \mathrm{Hab} . / \mathrm{ha}, \mathrm{o}$, lo que es lo mismo, 170 viviendas/ha. Caso completamente imposible, por cuanto la ley solo permite una edificabilidad máxima al suelo urbanizable equivalente a 75 viviendas/ha. En el momento de la tramitación de las DOT hubo alguna polémica mediática sobre la veracidad de la reducción de crecimiento que la propaganda oficial anunciaba. Ante las acusaciones de falsedad de tal reducción, véase la respuesta oficial que dio el gobierno en nota de prensa de 8-2-1999 (Cuadro № 3 ).

Obsérvese cómo la nota oficial, intencionadamente, elude ahora citar los 2,3 millones de plazas que la publicidad de las DOT decía que se descargarían de la CCUT. Ahora se insiste en que el techo urbanístico balear era de 4,3 millones de "plazas" y que las DOT desclasifican 4.500 "hectáreas". La propaganda de las DOT de 1999 confundía intencionadamente la posibilidad de crecimiento ex novo vía suelo urbanizable con la posibilidad de materialización de la edificabilidad que los suelos urbanos de las islas habían establecido.

Cuadro № 3

LA VERSIÓN OFICIAL DEL EFECTO SOBRE EL DIMENSIONADO DE LAS DOT (8-2-1999)

El Govern Balear vol tornar a destacar que el sostre poblacional fixat avui pels planejaments urbanístics en vigor és de 4.300 .000 habitants. Efectivament, la desclassificació de sòl prevista per les DOT és d'aproximadament 4.500 hectàrees. Però, a més, les DOT impedeixen un creixement superior al $10 \%$ a les Illes en un termini de deu anys, limitació aplicada al sòl urbà $i$ al urbanitzable i que retalla substancialment el sòl que els ajuntaments podran desenvolupar.

Per tant, les Directrius no només desclassifiquen sòl sinó que impedeixen la nova classificació en el futur.

Prohibició sense excepcions per fer noves urbanitzacions a 500 metres de la costa. Desclassificació dels projectes d'urbanització en qualsevol punt de la tramitació excepte quan les obres ja estan en marxa o ja aprovades

Limitació de la incorporació de nou sòl urbanitzable als municipis en funció d'un 0,85\% anual acumulable, equivalent al $10 \%$ en 10 anys. Aquesta limitació no admet excepcions. Aquesta restricció significa que, en un termini de deu anys, només es podrà donar cabuda a un increment poblacional del $14 \%$ en relació a la població actual.

En tots els municipis, obligació de vincular l'entrada de nou sòl al volum de sòl urbà pendent de desenvolupament, de manera que allà on hi ha més sòl pendent d'execució les possibilitats de créixer són menors i viceversa, sempre dins els marges globals del $10 \%$ de creixement en deu anys.

Fuente: Nota de prensa del Govern Balear de día 8 de febrero de 1999. 
El $10-12 \%$ de crecimiento contemplado en el artículo 33 de las DOT ha sido evaluado, como apuntamos más arriba, en 2.775,62 hectáreas, que a $100 \mathrm{p} / \mathrm{ha}$, equivalen a 277.562 plazas (Ferrer, 2001). Estas plazas deben sumarse a las ya "ordenadas" en suelo urbano, así como a las pendientes de ordenación en suelo urbanizable y que no quedaron desclasificadas en 1999 por aplicación de la disposición adicional 12 . Ambos sumandos alcanzarían los 3,5 millones de plazas.

La pregunta era: ¿cuántas "plazas" contenían las famosas 4.500 "hectáreas"? Los trabajos previos a las DOT contabilizaron las densidades del suelo urbanizable. Para el caso de Mallorca, tales indicadores fueron cuantificados en 57 y 27 plazas/hectárea, según fuera SUP o SUNP (GOVERN BALEAR, 1997:196). Suponiendo una densidad balear en suelo urbanizable de $60 \mathrm{p} / \mathrm{ha}$ (cifra muy elevada y difícilmente alcanzable), las 4.500 hectáreas desclasificadas tan solo habrían supuesto una descarga de 270.000 plazas, algo menos de las 277.532 $(2.775,62$ ha a $100 \mathrm{p} / \mathrm{ha})$ que permite clasificar el artículo 33 antes mencionado.

Ante tal evidencia es irrebatible que nos encontramos, nuevamente, ante límites al crecimiento sin efecto real por sobre elevación del listón del techo de la oferta urbanística con respeto a la demanda. Con lo cual, lejos de contener el crecimiento cuantitativo, el efecto más notable de la DOT de 1999, a corto-medio plazo, habrá consistido en desplazar aquel suelo urbanizable situado en localizaciones por las que la demanda no se había interesado, a las apetecibles orlas periurbanas de los núcleos existentes.

Se ha reordenado la localización de aquel suelo urbanizable que no se había materializado, por el que la demanda no se había interesado. Un suelo urbanizable que venía contemplado en unos planes municipales con frecuencia obsoletos, las DOT venían a desatascar las expectativas de crecimiento que, por diferentes motivos, no se habían materializado. De la tercera hipótesis "Ios planes no influyen en la evolución territorial" se había pasado a la segunda "los planes ordenan un crecimiento que no cuestionan".

\section{Las "virtudes" de las DOT}

Pese a la crítica que hemos expuesto deben reconocerse, como mínimo, dos virtudes a las Directrices de Ordenación Territorial de 1999:

- A corto plazo, concentran el nuevo crecimiento en las orlas periurbanas de los núcleos existentes ${ }^{11}$, cerrando la posibilidad de crecer aisladamente o en los primeros $500 \mathrm{~m}$ de costa, una ubicación que puede traer aparejados importantes problemas de gestión si, como ocurre normalmente, en las orlas periurbanas de $500 \mathrm{~m}$, la propiedad es mayoritariamente minifundista.

- Al demostrar que conteniendo el suelo urbanizable la actividad del sector de la construcción y la CCUT del territorio se mantienen inalteradas, descubren el suelo urbano como el gran yacimiento de crecimiento inmobiliario. Un hecho que hará explorar a algunas administraciones nuevos sistemas de regulación del crecimiento $^{12}$.

Los planes municipales y las determinaciones derivadas de las Directrices de Ordenación Territorial, por consiguiente, construyen un escenario de futuro que no restringe para nada el crecimiento cuantitativo de la oferta residencial y turística. Desde 1999 únicamente lo ordena y con anterioridad a esta fecha ni eso. Los escenarios tendenciales, a partir de estas mínimas determinaciones de la planificación municipal o territorial, es previsible que se vayan materializando al ritmo de la demanda exterior, al ritmo de la demanda de la gran megalópolis europea, como ha ocurrido en los últimos 50 años.

\footnotetext{
${ }^{11}$ El aspecto negativo de la concentración del crecimiento en las orlas periurbanas es que se urbaniza gran parte de los suelos de mayor calidad agrológica. En efecto, el modelo tradicional de asentamientos había transformado laboriosamente el entorno de los principales enclaves para la actividad agrícola construyendo un importante patrimonio que, ahora, se verá urbanizado.

12 Se trata de las medidas urbanísticas que analizamos en (Rullan, 2005).
} 


\section{El reparto efectivo del crecimiento por parte de los Planes Territoriales Insulares}

Como apuntábamos más arriba, en función de lo establecido por las DOT, son los PTI los encargados de atribuir la posibilidad de crecimiento residencial y turístico entre los municipios. Mientras tanto, el nuevo crecimiento turístico y residencial se veía limitado al suelo urbano, al urbanizable con plan parcial aprobado no desclasificado y al urbanizable que, aún sin contar con plan parcial y estar en plazos, se ubicaba en AT.

Tal circunstancia, pensamos, ha sido la responsable de que los PTI se hayan aprobado con una celeridad inaudita: el de Menorca en 2003, el de Mallorca en 2004 y el de Ibiza y Formentera en 2005. La no aprobación de los PTIs -competencia de los respectivos Consells Insulares- contenía la expansión de la mancha urbana. Una contención que solo podía salvarse con la aprobación del correspondiente PTI.

\section{a) El Plan Territorial Insular de Menorca}

El 25 de abril de 2003 el Consell Insular de Menorca aprobaba definitivamente su Plan Territorial Insular ${ }^{13}$, el primero después de la aprobación de las DOT (CIMe 2003a y 2003b).

El Plan Territorial Insular de Menorca, como harán posteriormente también los Planes de Mallorca e Ibiza-Formentera, desarroIlan la letra de las DOT y, como no podía ser de otra forma, a la hora de establecer los límites de crecimiento se limitan a autorizar a los ayuntamientos para clasificar un determinado número de nuevas hectáreas como suelo urbanizable.

Las DOT legitimaban al PTI menorquín a autorizar, según los criterios derivados del modelo territorial que quisiera adoptar, hasta 439,18 hectáreas de suelo urbanizable con una densidad de 100 plazas/ha, el $12 \%$ de las 3.659,85 hectáreas que, en 2003, eran suelo urbano y urbanizable con plan

\footnotetext{
13 Para mayores detalles dirigirse a la página web: http://www.cime.es/ca/ptinicial/index_pti_ inicial.html
}

parcial aprobado. Ello equivalía a un incremento vía nuevo suelo urbanizable de 43.918 nuevas plazas.

Sin embargo, el PTI de Menorca renunció a incorporar todo el crecimiento que las DOT les permitirían limitando el incremento de suelo urbanizable a 10.749 plazas (Art. 38 ), el $24 \%$ del techo establecido por las directrices de 1999.

Estas 10.749 plazas pueden materializarse en una horquilla de entre 60 y 120 plazas/ha en los municipios de Ciudadela y Mahón, y entre 60 y 90 plazas/ha para el resto. Ello equivale a decir que, como máximo, si los municipios optan por la opción más extensiva de 60 plazas/ha, el nuevo suelo a ocupar ascendería a 179 ha, el 41\% de lo permitido por las DOT, y en caso de optar por la opción más intensiva, únicamente se alcanzarían 102 hectáreas, el 23\% de lo permitido por las DOT (Cuadro $n^{\circ} 4$ ).

b) El Plan Territorial Insular de Mallorca

Veinte meses más tarde que el de Menorca, el 13 de diciembre de 2004, veía la luz el Plan Territorial Insular de Mallorca.

Para el caso de Mallorca las DOT de 1999 permitían a su PTI un reparto de crecimiento equivalente al $10 \%$ de su suelo urbano (15.580 ha) y urbanizable con plan parcial aprobado (3.361 ha). Ello equivalía a 1.894 ha que, a 100 plazas/ha, podría suponer un incremento de 189.410 plazas.

El PTI de Mallorca ${ }^{14}$, como tampoco hiciera el de Menorca, no llega al límite de sus posibilidades según las DOT fijando un reparto de crecimiento de 1.491 ha $y$ 70.403 plazas (Cuadro № 4).

El reparto de este crecimiento entre los municipios se lleva a cabo a partir de cuatro criterios diferentes que generan cuatro tramos de crecimiento en hectáreas para cada municipio. Dos de ellos se establecen en proporción al modelo territorial vigente, se

\footnotetext{
14 Para mayores detalles dirigirse a la página disponible en Internet: http://www.conselldemallorca.net/ platerritorial/
} 
trata del tramo proporcional a la población y al suelo residencial de cada municipio. A estos dos tramos se les asignan el 30\% de las 1.491 hectáreas a repartir $-15 \%$ a cada uno de ellos-. Los otros dos son establecidos con vistas a favorecer el modelo territorial que se pretende impulsar y serán los responsables del reparto del $70 \%$ restante de las 1.491 hectáreas. Se trata de los tramos destinados a operaciones de reconversión $(47 \%)$ y reequilibrio territorial $(23 \%)$. El primero es un tramo de crecimiento destinado a la reconversión de las zonas turísticas mediante intercambio de aprovechamientos entre zonas turísticas que requerirán nuevos suelos para atender a las nuevas demandas más exigentes en suelo. El segundo pretende consolidar la capitalidad de Palma e impulsar las cabeceras urbanas de Inca y Manacor.

Consecuentemente, a partir de los valores municipales de población y suelo residencial se lleva a cabo un reparto intermunicipal "objetivo" de crecimiento entre los diferentes términos municipales, ello representa el 30\% del total. El 70\% restante se reparte de forma "cualitativa" y responde a las acciones concretas del plan para llevar a cabo operaciones de reconversión y de reequilibrio territorial. c) El Plan Territorial Insular de Ibiza y Formentera

El de Ibiza y Formentera, con la aprobación definitiva de día 21 de marzo de $2005^{15}$, fue el último en cerrar la serie de planes territoriales insulares. Se trata de un plan que va al máximo de las posibilidades de crecimiento que permiten las DOT, el $10 \%$, y para el reparto intermunicipal del mismo aplica el mismo criterio que las DOT: cada municipio, conforme a lo dispuesto en su norma 27.1, podrá clasificar nuevo suelo residencial y turístico en una cantidad no superior al $10 \%$ de suelo urbano y urbanizable con plan parcial aprobado definitivamente en 1999, cuando se aprobaron las DOT (Cuadro № 4 ).

Por tanto, contrariamente a lo que hicieron los PTIs de Menorca y Mallorca, en este caso, no se rebaja el listón de crecimiento de las DOT y no se establecen criterios propios para repartir este crecimiento.

d) El crecimiento autorizado por los planes insulares en relación al permitido por las DOT

Como consecuencia de la aprobación definitiva de los correspondientes Planes Te-

\section{Cuadro № 4}

LAS PREVISIONES DE CRECIMIENTO DE LOS PLANES INSULARES DE MENORCA (2003-2013), MALLORCA (2004-2014) E IBIZA-FORMENTERA (2005-2015)

\begin{tabular}{|c|c|c|c|c|c|c|}
\hline \multirow{2}{*}{ Islas } & \multicolumn{2}{|c|}{ DOT'99 } & \multicolumn{4}{|c|}{ Planes Territoriales Insulares } \\
\hline & $\mathrm{Ha}$ & Plazas & $\mathrm{Ha}$ & $\%$ & Plazas & $\%$ \\
\hline Menorca & 439 & 43.918 & $102-179$ & $23-42$ & 10.749 & 24 \\
\hline Mallorca & 1.894 & 180.941 & 1.491 & 79 & 70.403 & 39 \\
\hline Ibiza y Formentera & 442 & 44.200 & 442 & 100 & 44.200 & 100 \\
\hline Total & 2.775 & 269.059 & $2.035-2.214$ & $73-80$ & 125.352 & 47 \\
\hline
\end{tabular}

Fuente: Elaboración propia a partir de CIMe 2003a y 2003b; http://www.conselldemallorca.net/platerritorial y http://www.cief.es/pti2004/definitiu/index.htm.

\footnotetext{
15 Para mayores detalles dirigirse a la página disponible en Internet: http://www.cief.es/pti2004/definitiu/index.htm
} 
rritoriales Insulares, se abre la posibilidad de clasificación entre 2.035 y 2.214 hectáreas de nuevo suelo residencial y turístico para los horizontes temporales de cada uno de ellos. Tal posibilidad, que supondría poner en juego 125.352 nuevas plazas de las 269.059 que posibilitaban las DOT (Cuadro № 4), se irá materializando en función de que los planes urbanísticos municipales revisen sus planeamientos y clasifiquen todas o parte de las hectáreas que les han correspondido en el reparto.

La cronología de redacción de los planes insulares, siguiendo una dirección NE-SW, ha ido incrementando las posibilidades de crecimiento que abrían las DOT, desde el $24 \%$ de Menorca hasta el $100 \%$ de IbizaFormentera. Como puede observarse, el modelo territorial vigente ha pesado más que su posible modificación, abriendo las posibilidades de nuevo crecimiento residencial y turístico en proporción directa al grado de urbanización de cada una de las islas.

Del análisis de la capacidad de carga urbanística de los diferentes planes municipales así como de los planes que se sitúan a escala territorial (DOT y PTIs) se deduce que estos no han supuesto ninguna contención al crecimiento, simplemente se han limitado a colocar la demanda de nuevo suelo residencial y turístico en las orlas periurbanas (áreas de transición) sin cuestionar el crecimiento en la ciudad ya urbanizada (suelo urbano). Los planes, en todas sus escalas, han ordenado el crecimiento cuantitativo, no lo han cuestionado, calmado ni contenido. En estas circunstancias ha sido la política económica y financiera la que ha dirigido la política urbana y territorial.

Se impone, por tanto, de cara a abordar políticas de sostenibilidad territorial a medio-largo plazo, incidir especialmente en las políticas que normalmente se consideran al margen del urbanismo y la ordenación del territorio: la política económica y, especialmente, la financiera.

\section{Referencias bibliográficas}

AGUILÓ, E. y VERGER, A. El urbanismo y el medio ambiente en las Baleares. Palma: CGI/CEH/Banca March, 1982.
ARTIGUES, A.; BAUZÀ, A.; BLÁZQUEZ, M.; GONZÁLEZ, J. M.; MURRAY, I. y RULLAN, O. Introducción a la Geografía Urbana de las Illes Balears. Guía de campo. Palma: IBATUR/Fundació Baleària, 2006.

BENAVENT, M. La Ordenación del Territorio en España. Evolución del concepto y de su práctica en el siglo XX. Sevilla: Universidad de Sevilla/Consejería de Obras Públicas y Tranportes, 2006.

BLASCO, A. Planificación y gestión del territorio turístico de las Islas Baleares. Ordenación y gestión del territorio turístico, 2002, p. 215-284.

BLÀZQUEZ, M.; MURRAY, I. y GARAU, J. M. El tercer boom. Indicadors de sostenibilidad del turisme de les Illes Balears 1989 - 1999. Palma: Lleonard Muntaner, 2002.

BUADES, J. Exportando paraísos. La colonización turística del planeta. Palma: La Lucerna, 2006.

CAIXA DE LES BALEARS. Evolución Económica. Informe económico anual publicado desde 1973 por la Caixa de les Balears. Palma: Caixa de les Balears, 1973-2007.

CIME. Menorca, un projecte territorial sostenible. Memòria del Pla Territorial Insular. Maó: Consell Insular de Menorca, 2003a.

CIME. Pla Territorial Insular de Menorca. Normes del Pla Territorial Insular de Menorca. Maó: Consell Insular de Menorca, 2003b.

ESTEBAN, J. La ordenación urbanística: conceptos, herramientas y prácticas. BarceIona: Ed. Electa y Diputació de Barcelona, 2003.

FERRER, A. Estudi del sòl vacant a les Illes Balears (2000). Palma: Govern de les Illes Balears, 2001.

GOVERN BALEAR. Directrius d'Ordenació Territorial. Anàlisi i Diagnòstic. Palma: Govern Balear, 1997.

PONS, A. Evolució dels usos del sòl a les illes Balears: 1956 - 2000. Territoris, 2003, № 4, p. 129-145. 
RULLAN, O. Estructuras territoriales planificadas estudiadas mediante análisis multivariado. Norba, Geografía, 1989, № VIII IX, p. 623-638.

RULLAN, O. Legislación balear versus territorio y medio ambiente. En: VILA, A. y PUJOL, J. L. Turismo y territorio. Palma: COAB, 1995, p. 153-178.

RULLAN, O. Crecimiento y política territorial en las Islas Baleares (1995-2000). Estudios Geográficos, 1999, № 236, p. 403-442.

RULLAN, O. Ordenación y gestión del litoral turístico. En: BLÀZQUEZ, M.; CORS, M., GONZÁlEZ, J. y SEGUí, M. Geografía y territorio. El papel del geógrafo en la escala local. Palma: Universitat de les Illes Balears, 2002, p. 21-36.

RULLAN, O. Una técnica urbanística para contener el crecimiento residencial en espacios con fuerte presión inmobiliaria. Geo Crítica/Scripta Nova. Revista electrónica de Geografía y Ciencias Sociales, 2005, № 194-32. Disponible en Internet: http:// www.ub.es/geocrit/sn/sn-194-32.htm.

RULLAN, O. L'ordenació territorial a les Balears (segles XIX - XX). Palma: Ediciones Documenta, 2007.

SITIBSA Estudi de la capacitat d'allotjament del sòl vacant a 31 de desembre del 2001. Palma: Govern de les Illes Balears, 2002.

SOCíAS, J. M. Evolución de la legislación turística en las islas Baleares. Revista Aragonesa de Administración Pública, 1998, № 13, p. 197-234.

SOCíAS, J. M. La ordenación de las zonas turísticas litorales. Madrid: Instituto Pascual Madoz, 2001. 
